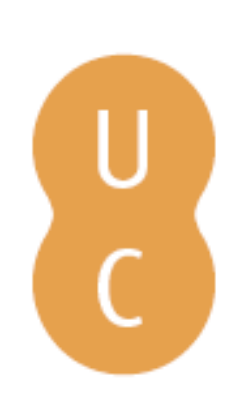

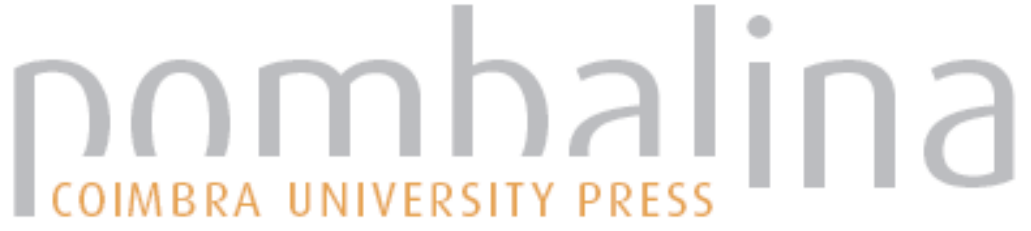

\section{Carrisso: implicações no desenvolvimento da Botânica}

\author{
Autor(es): Sales, Fátima \\ Publicado por: Imprensa da Universidade de Coimbra \\ URL \\ persistente: URI:http://hdl.handle.net/10316.2/32501 \\ DOI: $\quad$ DOI:http://dx.doi.org/10.14195/978-989-26-0363-6_2
}

Accessed : $\quad$ 26-Apr-2023 05:18:55

A navegação consulta e descarregamento dos títulos inseridos nas Bibliotecas Digitais UC Digitalis, UC Pombalina e UC Impactum, pressupõem a aceitação plena e sem reservas dos Termos e Condições de Uso destas Bibliotecas Digitais, disponíveis em https://digitalis.uc.pt/pt-pt/termos.

Conforme exposto nos referidos Termos e Condições de Uso, o descarregamento de títulos de acesso restrito requer uma licença válida de autorização devendo o utilizador aceder ao(s) documento(s) a partir de um endereço de IP da instituição detentora da supramencionada licença.

Ao utilizador é apenas permitido o descarregamento para uso pessoal, pelo que o emprego do(s) título(s) descarregado(s) para outro fim, designadamente comercial, carece de autorização do respetivo autor ou editor da obra.

Na medida em que todas as obras da UC Digitalis se encontram protegidas pelo Código do Direito de Autor e Direitos Conexos e demais legislação aplicável, toda a cópia, parcial ou total, deste documento, nos casos em que é legalmente admitida, deverá conter ou fazer-se acompanhar por este aviso.

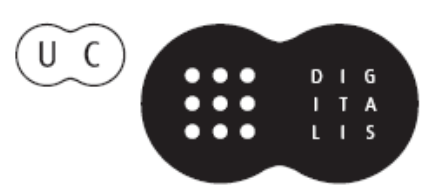




\section{HELENA FREITAS PAULO AMARAL ALEXANDRE RAMIRES FÁTIMA SALES \\ Coordenaçã̃o}

\section{Missão}

\section{Botânica}

Angola

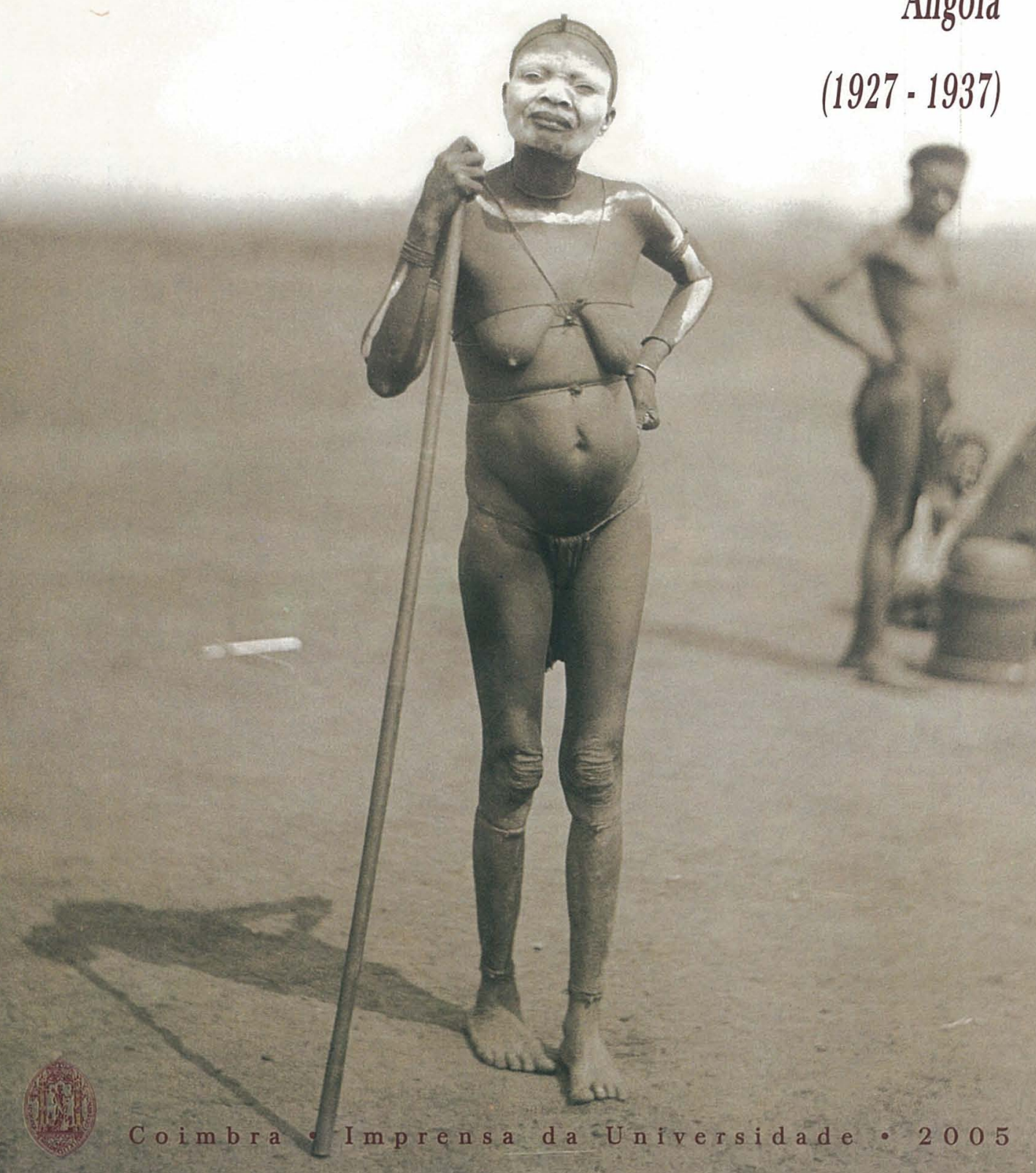


COORDENAÇÃO EDITORIAL

Imprensa da Universidade de Coimbra

\section{Edição de Imagem}

Paulo Amaral

Alexandre Ramires

\section{ConcepÇÃo GráficA \\ António Barros}

\section{PaginaCĩo}

António Resende

[Universidade de Coimbra]

\section{EXECUÇÃO GRÁFICA}

Imprensa de Coimbra, Lda.

Largo de S. Salvador, 1-3

3000-372 Coimbra

\section{Foto DA CAPA}

Mulher indígena.

Os traços brancos sobre o corpo são sinal de luto por morte do soba a quem ela pertencia.

Posto do Nordeste (Lunda), Julho 1927

ISBN

972-8704-41-0

DEPOSITO LEGAL

$223714 / 05$

(C) Fevereiro 2005, Imprensa da Universidade de Coimbra

OBRA PUBLICADA COM O PATROCÍNIO DE: 
helena freitas

Paulo AMaral

ALEXANDRE RAMIRES

FÁtima SALES

Coordenação

Missão Botânica

Angola 1927-1937

Coimbra - Imprensa da Universidade 

Fátima Sales

Presidente da Sociedade Broteriana

Departamento de Botânica da FCTUC

\section{CARRISSO: IMPLICAÇÕES NO DESENVOLVIMENTO DA BOTÂNICA}

Luiz Wittnich Carrisso nasceu na Figueira da Foz a 14 de Fevereiro de 1886, filho de Ignácio Augusto Carrisso e Leopoldina Wittnich, de origem holandesa. Faleceu repentinamente de síncope cardíaca aos 51 anos a 14 de Junho de 1937 no deserto do Namibe (previamente Moçâmedes e Mossamedes), em Angola, no final da sua terceira expedição científica a este país. Por esta altura Carrisso tinha uma longa história de homem das ciências e homem público; era há 19 anos Professor Catedrático da Faculdade de Ciências da Universidade de Coimbra e Director do Instituto Botânico Júlio Henriques. Estava acompanhado por sua esposa, Ana Maria de Sousa Wittnich Carrisso, Francisco da Assunção Mendonça (naturalista do Instituto Botânico de Coimbra), Jara de Carvalho (assistente do Instituto Botânico de Coimbra), Francisco de Sousa (colector do Instituto Botânico de Coimbra), Arthur Wallis Exell (naturalista do British Museum, Londres) e esposa e John Gossweiller (botânico suíço ao serviço de Portugal em Angola). As suas expedições a Angola eram o início de dois sonhos. Um, estudar a flora de Angola em profundidade. O outro, descreveu-o ele próprio após a sua segunda expedição, aquando da sua conferência Ocupação Científica das Colónias Portuguesas na 1. ${ }^{\text {a }}$ Exposição Colonial Portuguesa no Porto em 1934:

«...a colonização tem de ser feita cientificamente, dando a esta palavra o seu significado mais vasto... a criação de um instituto de investigação científica colonial... Com o decorrer do tempo, e o progressivo desenvolvimento destes serviços, alargar-se-iam os quadros dos institutos interessados, creando-se, assim, um importante corpo de investigadores... A organização do nosso museu colonial seria o coroamento dêste plano. Não temos hoje, nem material, nem pessoal para êsse empreendimento: mas dentro dalguns anos, estou certo de que isso seria possível, desde que lançássemos já mãos à obra. 
O nosso museu colonial! Confrange-se-me o coração, quando vejo a nossa pobreza, e faço o confronto com o que sucede nos outros países...».

Colonialista fervoroso aplicou-se a dar a conhecer, de diversas formas, o "país de além-mar». Não parece, contudo, estarmos perante um homem arrogante do seu império. É referido em jornais da época (O Figueirense, Correio da Manhã, Diário de Coimbra) como pessoa querida e respeitada e no seu funeral participaram pessoas de todas as classes, desde as mais humildes às mais elevadas. Carrisso era, isso sim, um naturalista empreendedor e curioso que se irritava com a passividade portuguesa. Apercebia-se do manancial de informação que estava à beira do conforto desfrutado por uma classe culta, lânguida, de horizontes só até à beira-mar, classe culta que do império viu o óbvio ouro do Brasil e pouco mais.

Esta última conferência (Ocupação Científica das Colónias Portuguesas) revela um Carrisso impaciente (e singularmente intemporal...) para com um país morno, de brandas ambições. A sua atitude crítica pode estar curiosamente relacionada com o telegrama de condolências mais curto que a Universidade de Coimbra recebeu pela sua morte - o de Salazar: 26 palavras, das quais 5 são Universidade, professor, doutor, Luiz e Carrisso. Perante uma larga audiência, Carrisso é claro: «Se em muitos dos seus as-

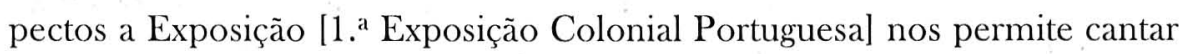
vitória, outros há em que devemos confessar o nosso atrazo. Assim acontece, particularmente, com a investigação científica colonial. Honrado com um convite, para tratar deste assunto, como complemento à Exposição, dele me vou ocupar, e não faltarei ao que devo à minha Pátria, e a mim próprio, ocultando a verdade com fantasias sempre agradáveis de dizer e de ouvir. Qual é o nosso activo? Alguma coisa temos feito, seria faltar à verdade não o reconhecer. Mas o que fizemos pertence a um passado que começa já a ser remoto... dia a dia temos conhecimento de expedições estranjeiras que percorrem as terras portuguesas de além-mar, recolhendo cuidadosamente aquilo que desprezamos... perante a falência da iniciativa portuguesa, as iniciativas estranjeiras se multiplicam, corrigindo assim, mas de uma forma desprestigiante para nós, a nossa incúria em cuidar do que é nosso ... Não fui pessimista, nem o sou, toda a minha vida o atesta. Mas não vejo qualquer vantagem em encobrir a verdade, ainda que ela seja desagradável. E essa verdade é que, em matéria de investigação científica colonial estamos numa fase de grande atrazo, senão de decadência. 
Continuaremos nós a contemplar as glórias do passado sem repararmos nas exigências do tempo presente?"

Carrisso foi um homem com muitas facetas, algumas, pelo menos aparentemente, contraditórias: fascinado por África e a sua diversidade que tanto queria estudar; surdo às vozes para a independência que já se faziam ouvir pelo mundo. Foi um homem do seu tempo. A sua postura colonialista era paternalista e cristã como a de outros seus contemporâneos tais como a do missionário, médico e músico suíço Albert Schweitzer (1875-1965). Mas acima de tudo, Carrisso revela-se uma pessoa que pensava por si própria.

Quem o conheceu referiu que Carrisso era um homem trabalhador «de invulgar espírito organizador e de excepcionais capacidades realizadoras" (Fernandes, 1939). Certamente que o era. Pela obra que deixou é obvio que era intelectualmente dotado. Mas, a não ser que trabalhasse muito e fosse muito metódico, onde iria ele buscar tempo para todas as actividades a que se dedicou como homem público (isto num tempo sem emails e Microsoft Word...) para além da sua dedicação à botânica?! Carrisso foi Presidente da Junta das Construções para o Ensino Técnico e Secundário, Secretário da Faculdade de Ciências, Presidente da Câmara Municipal de Coimbra, Vice-Reitor da Universidade, foi delegado do governo português à Conferência Internacional para a Protecção da Fauna e Flora da África em Londres (1931) - para não falar dos seus afazeres no "Tennis-Club" da Figueira da Foz, etc., etc...

A vida de Carrisso como botânico terá tido óptimos auspícios nas mãos competentes de Ruy Telles Palhinha (1871-1957) nas aulas de Ciências Naturais de liceu, em Lisboa. Ficaram amigos para sempre. Aos 22 anos licenciou-se com 19 valores na Faculdade de Filosofia Natural da Universidade de Coimbra. Foi, pois, aluno de Júlio Henriques. Aos 25 anos doutorou-se na Faculdade de Filosofia Natural com a tese «Materiais para o estudo do plâncton na costa portuguesa - fascículo I» da qual foi examinador Júlio Henriques; a 'lição de escolha' do seu doutoramento foi «Estado actual dos conhecimentos àcerca dos restos fósseis de Neanderthal, Spy e Krapina» da qual foi examinador Eusébio Tamagnini. Aos 26 anos foi nomeado assistente do grupo de Ciências Biológicas da então já Faculdade de Ciências tendo apresentado para esse concurso o trabalho «Materiais para o estudo do plâncton na costa portuguesa - fascículo II.» Nos 6 anos 
seguintes Carrisso esteve imerso em docência. Júlio Henriques estava nos seus anos 70 e dedicava-se essencialmente 'à menina dos seus olhos', ou seja, o Herbário. Na sequência do jubileu de Júlio Henriques em 1918 Carrisso foi nomeado professor catedrático e, no mesmo ano, com 32 anos, foi nomeado o $15 .^{\circ}$ director do Jardim Botânico. Cerca de um ano depois Aurélio Quintanilha foi para Coimbra e partilhou com ele a tarefa da docência o que lhe permitiu passar o ano de 1920 na Suíça no laboratório de Robert Chodat.

Alívio. Alívio infinito e entusiasmo deve ter sido o que Carrisso sentiu ao ir para a Suíça. Um ano exclusivamente dedicado à investigação - e num dos melhores laboratórios europeus da época! Terá regressado de mente apaziguada e cheio de energia. Duas publicações são o resultado dessa investigação que não teve oportunidade de retomar (Chodat \& Carrisso, 1920; Chodat avec la collab. de Carrisso, 1920). Carrisso não podia ter escolhido melhor para alargar os seus horizontes do que trabalhar com Chodat. Provavelmente os seus contactos com o famoso suíço resultavam do interesse comum em algas. Mas Chodat trabalhou, a bem dizer, em tudo o que lhe passava pelas mãos! Florística, citologia, algas, genética, fungos, etc. e em mirmecofilia [relação entre formigas e outros organismos]! Assim, Carrisso investigou, durante um ano, as relações entre o género Cordia (Borraginaceae) do Paraguai e os ninhos que as formigas fazem nos troncos destas árvores.

Provavelmente o próprio Carrisso teria dividido a sua carreira em quatro períodos: algologia, «incubação», «organização» e África, tendo o último decorrido entremeado com o anterior.

Como licenciado pela escola de Júlio Henriques, Carrisso tinha formação clássica lineana essencialmente em plantas vasculares, mas em breve mostrou a sua individualidade e encontrou o seu próprio caminho. Sendo um homem da beira-mar foi exactamente o mar a sua primeira atracção: o fitoplancton da baía de Buarcos que colhia num barco à vela e estudava num pequeno laboratório que instalou em sua própria casa na Figueira da Foz. Terá sido um período da sua vida bastante solitário (Carvalho, 1939) o que parece contrastar com o resto da sua carreira. $\mathrm{O}$ aspecto mais inovador do seu trabalho foi a ênfase que deu aos aspectos ecológicos dos grupos que estudou: Flagelliae, Dinoflagelliae, Cystoflagelliae e Bacillariales. A classificação que mais se aproxima desta é a da obra Süsswasserflora (da 
Alemanha, Áustria e Suíça) editada pelo seu contemporâneo Adolf Pascher (1881-1945), alemão que trabalhou grande parte da sua vida na Universidade de Praga. Os aspectos ecológicos certamente que terão resultado do seu estudo da obra do alemão Franz Schütt (1892). Carrisso podia ser um jovem investigador perdido no extremo sudoeste da Europa mas, nem por isso deixava de ser cosmopolita! Este trabalho promissor teve um fim dramático quando foi nomeado para o cargo de assistente e foi totalmente submergido pela docência. Terá este sido um período algo desanimador para o jovem botânico? Ao início brilhante de uma carreira como investigador seguiu-se o ensino numa instituição em decadência, comandada por um líder que fora brilhante na força da idade mas, agora, já cansado para lidar com as consequências da Primeira Guerra - e provavelmente sem se aperceber disso. Não, não penso que esse tempo tenha sido desanimador para Carrisso! Enquanto o Mestre dispunha de toda a autoridade o assistente teria delineado um plano para acudir a todos os aspectos do Jardim Botânico que estavam a precisar de um balão de oxigénio - e todos os aspectos precisavam de oxigénio desde a docência, ao jardim, aos laboratórios, passando pela biblioteca, a Sociedade Broteriana, o Herbário, a troca de sementes e o próprio edifício. Este terá sido o seu período de «incubação».

Ao ocupar o cargo de director do Jardim Botânico Carrisso estava só perante uma enorme tarefa pois, a pior das desgraças que tinha caído sobre a instituição tinha sido a erosão de pessoal o qual se foi reformando à medida que Júlio Henriques envelhecia. $\mathrm{O}$ que se seguiu nas mãos do homem empreendedor que era Carrisso deve ter sido como um fogo de artifício que durou 19 anos!

Carrisso era um homem metódico. Primeiro havia que pôr a casa em ordem! O principal problema era o escasso pessoal; o outro era a escassa dotação (como os problemas se repetem!). Carrisso dividiu o já então Instituto Jardim Botânico Júlio Henriques em 3 secções: Laboratório, Herbário e Jardim. A responsabilidade do Laboratório e algumas das aulas entregou com toda a confiança ao novo colaborador que aceitou o seu convite para ir para Coimbra, Aurélio Quintanilha. A este se juntaram mais tarde Abílio Fernandes, $\Lambda$. Taborda de Morais e J. Barros Neves. Foram instaladas salas de esterilização, culturas de algas e outras, câmara de fotografia e microfotografia. Foram desenvolvidas as áreas de citologia, anatomia, micologia e genética. 
O Herbário constituía um problema mais delicado, porque Carrisso não desejava ferir a susceptibilidade do Mestre. Em 1921 convidou para o lugar de assistente e jardineiro chefe o licenciado Francisco d'Ascenção Mendonça. Carrisso organizou as coisas de modo a que Mendonça fosse, gradualmente, substituindo Júlio Henriques nas suas funções de naturalista e, definitivamente, quando este faleceu. Deu inicio a uma colecção de criptogamia e a uma algoteca. Organizou várias herborizações em Portugal. Desenvolveu a colaboração com amadores, alguns antigos alunos, que regularmente enviavam material de outros países africanos (à altura, colónias portuguesas).

A solução para o Jardim não terá sido a contento de Carrisso, pois ficou à sua responsabilidade directa e tirava-lhe horas de sono... Mas reconstruiu as estufas e construiu uma para plantas aquáticas tropicais. Contudo, as maiores ralações terão sido as que teve por causa do edifício propriamente dito quando parte das instalações, já exíguas, foram retiradas ao Instituto a favor do Liceu José Falcão. Carrisso chegou mesmo a pedir a demissão.

A Sociedade Broteriana estava muito desmotivada à data da morte de Júlio Henriques. Contudo, era óbvia a sua importância para o enriquecimento, quer do Herbário, quer da Biblioteca. Carrisso alargou o âmbito do Boletim com artigos sobre citologia e genética vegetal dando início em 1922 à 2. ${ }^{\text {a }}$ série do mesmo. Iniciou em 1930 as Memórias e em 1935 o Anuário da Sociedade. Como resultado destes investimentos as trocas com revistas científicas estrangeiras subiram exponencialmente.

As aulas práticas eram dadas nos laboratórios e no Herbário. Carrisso foi descrito por vários (Fernandes, 1939; Silva Dias, 1986) como um pedagogo moderno. Adivinha-se o professor inspirador que terá sido com a visão global que demonstrou ter do mundo e da vida. Vejamos: no seu doutoramento prestou especial atenção às características ambientais das águas da baía de Buarcos; os temas que escolheu ensinar: Ecologia, Fitogeografia e Botânica Sistemática; em África interessou-se pelo todo, a botânica, a agricultura, a etnografia, a qualidade de vida. Além do mais, ele próprio deu várias conferências e convidou vários professores estrangeiros a expor aspectos recentes da botânica.

Como resultado de todo este investimento em qualidade a produção científica durante o seu tempo como director envolveu 9 investigadores e foram publicados 62 artigos (Fernandes, 1939). 
Então, o mar chamou-o mais uma vez. Mas agora apenas como meio para chegar a África. Foi realizar «os sonhos».

As suas actividades em África duraram 10 anos e a semente terá sido um comentário fortuito, mas cheio de significado, de um botânico do Royal Botanic Gardens Kew a quem Carrisso se dirigiu sobre Moçambique. A resposta continha as seguintes palavras: «There is probably no part of Africa of which the flora has been so little investigated as Portuguese East Africa" (Correia, 1939). Estas palavras devem ter sido como um rastilho no homem de horizontes largos, pensamento claro e determinado que era Carrisso. A sua capacidade em dar solução a situações impossíveis já tinha sido demonstrada e cimentada com a revolução que em 9 anos tinha produzido em Coimbra. Fazer explorações científicas em África era só mais uma missão impossível. Na realidade, em Portugal ninguém estava interessado, nem em investigação, nem em África. Um investigador era um excêntrico e África era uma desconfortável maçada!

Inicialmente Carrisso pensou em Moçambique. Mas os escolhos encontrados na organização de uma expedição foram tais, que acabou por se decidir por Angola, já que tinha relações de amizade com o Secretário Provincial da Agricultura nesta província, Torres Garcia, seu antigo discípulo.

A 1 de Junho de 1927 Carrisso e Mendonça partiram para a primeira Missão Botânica a Angola. A verba era pouca e, portanto, a organização foi modesta contando apenas com simples material para herborizações e equipamento fotográfico. Viajaram em condições difíceis como era, aliás, costume na época em África e está patente em várias memórias fotográficas. Adivinha-se a emoção com que, tão longe da sua Figueira e da vegetação familiar da Serra da Boa Viagem, Carrisso (e Mendonça) terá ouvido o familiar linguarejar português! Mais de metade do tempo passaram-no na zona remota do noroeste de Angola, mas também visitam o deserto do Namibe (Moçâmedes) (Carrisso, 1929-30) - o que o há-de ver morrer 10 anos mais tarde... Mendonça (1929-30) descreveu mais tarde o habitat extremo de Welwitschia mirabilis Hook. f.: uma zona onde a flora tem um carácter xerófilo extremo com algumas acácias baixas de copa horizontal plana, chuvas extremamente raras mas nevoeiros nocturnos muito densos, solo xistoso arcaico.

Foram ainda a Cabinda e ao Congo Belga. Chegaram a Lisboa a 13 de Dezembro do mesmo ano com grande quantidade de material. 
Totalmente enfeitiçado (quantos o não ficam??) por África, Carrisso regressou a Portugal desta feita com duas missões: uma, voltar a África e continuar o estudo das vastidões perdidas em mistério; outra, como tão bem expressou Abílio Fernandes (1939), levar a cabo a «evangelização colonial da metrópole». As suas palestras sobre África eram colonialistas, sim, mas também informativas e entremeadas com momentos de humor.

No ano seguinte, em 1928, publicou no Boletim da Agência Geral das Colónias dois grandes projectos: um, nunca se concretizou (não dependia apenas de Carrisso...); o outro tratava da «Missão Académica a Angola» que teve lugar de imediato, em 1929. A expedição foi pensada com um grande sentido pedagógico, como uma grande aula prática de campo. Nela participaram 22 pessoas entre professores universitários de todo o país, alunos universitários dos últimos anos, Mendonça, Carrisso e Ana Maria, sua esposa (ao lado de um grande homem está, geralmente, uma grande mulher...). A experiência científica e pessoal deve ter sido qualquer coisa de único na vida daquelas pessoas tendo-se estabelecido uma ligação profunda entre os membros da expedição. Partiram de Lisboa a 10 de Agosto, percorreram $6.000 \mathrm{~km}$ em Angola onde estudaram a flora, a fauna, as potencialidades económicas, as condições de vida social e os problemas locais (Carrisso, 1928). A viagem fez-se, primeiro de barco, ao longo da costa, depois utilizando o sistema ferroviário e depois por estrada - uma aventura de fazer doer os ossos, mas que teve os seus momentos de smoking! Carrisso não resiste a mostrar ao grupo o fascínio do deserto a sul. De regresso passaram por São Tomé onde admiraram a sua vegetação tropical.

Durante estas duas explorações científicas a Angola foi colhido muito material vegetal. Durante 3 anos Carrisso e Mendonça prepararam um Syllogue Florae Angolensis [sumário de colecção de exemplares] do material colhido. Ao trabalhar nesse material, arquivá-lo, determiná-lo e tentar lidar com a sua nomenclatura foi reconhecida a necessidade de, como recomenda a boa metodologia taxonómica, compará-lo com a maior quantidade de material possível e estudar a bibliografia relevante. Uma vez mais Carrisso não aceita um não do destino. Não havia grandes colecções de África em Coimbra; não havia ainda uma grande biblioteca; como colaborador contava apenas com Mendonça. Carrisso sabia perfeitamente que as melhores colecções e conhecimentos sobre a flora de Angola estavam em Londres, no British Museum. Finalmente conseguiu que fosse estabelecida a cola- 
boração oficial entre o Conselho da Faculdade de Ciências da Universidade de Coimbra e o British Museum para a elaboração da obra Conspectus Flora Angolensis, obra de âmbito incomparavelmente maior do que o preliminar Syllogue. Em 1934 convidou Exell (naturalista experimentado em trabalho de campo e de herbário) para tomar conhecimento dos trabalhos já iniciados em Coimbra. Convidou também Gossweiller com o mesmo objectivo. Organizou a visita de Mendonça aos herbários de Londres e Berlim-Dahlem tornando-o num naturalista cosmopolita. Paralelamente, Mendonça preparou um estudo das tribos Maydaeae e Andropogoneae (Poaceae) de Angola onde seguiu o tratamento taxonómico de Stapf na Flora of Tropical East Africa, vol 9. A publicação envolve 38 géneros e 97 espécies com algumas citações bibliográficas e de material de herbário, dados sobre ecologia e distribuição geográfica. A importância desta família em Angola, principalmente no sul determinou o empenho de Mendonça neste trabalho.

Gradualmente o Syllogue foi absorvido pelo primeiro fascículo do primeiro volume da obra Conspectus Flora Angolensis o qual foi, mais tarde, encadernado com o segundo fascículo.

Conspectus Flora Angolensis (Consp. Fl. Angol.)

Elaborado pelo Instituto Botânico de Coimbra com a colaboração do Museu Britânico (British Museum).

Fundado por L. Wittnich Carrisso ( $\dagger)$.

Volume 1: Rananculaceae - Aquifoliaceae por A. W. Exell \& F. A. Mendonça (Flacourtiaceae por H. Sleumer, Dipterocarpaceae por H. Bancroft).

Publicado em 2 fascículos:

Fascículo 1 - pp ix-xxiv [Prefácio por Carrisso em português e inglês; Introdução por Mendonça em português e inglês], pp 1-176 (30 de Janeiro de 1937).

Fascículo 2 - pp i-viii [fotografia de Carrisso com assinatura, Sumário, Lista das 21 gravuras, 26 Nomes novos deste volume, 4 ilustrações, Mapa pequeno de Angola com distritos da divisão administrativa de 1927], pp 177-422 (20 de Agosto de 1951). Gravuras 21; pp 1-348: chaves, sinonímia, distribuição, ecologia; pp 349-376: Agenda e Corrigenda/Addenda and Corrigenda; pp 377-400: Sinopse das famílias tratadas; pp 401-422: Índice 
dos nomes botânicos; Mapa desdobrável de Angola com distritos da divisão administrativa de 1927, 1:6.000.000.

Bertrand (Irmãos), L. da, Lisboa.

O Conspectus propriamente dito (pp 1-348) inclui 57 famílias que seguem, no geral, a ordem de Bentham \& Hooker, Genera Plantarum. As chaves para as famílias foram deixadas para quando todo o trabalho estivesse terminado na totalidade, embora haja uma sinopse descritiva das famílias. Dentro de cada família há uma chave dicotómica para identificação dos géneros, no total de 238; dentro de cada género há uma chave dicotómica para a identificação de cada espécie as quais são em grande número; taxa inferiores à espécie são colocados em sinonímia. Para cada espécie é referido o autor, local de publicação do protologo, bibliografia relevante; sinonímia e respectiva bibliografia por ordem cronológica; distribuição geográfica por distritos indicando o Herbário onde está depositado o respectivo exemplar; hábito e ecologia; distribuição geográfica mundial. Na figura 1 estão as páginas 190 e 191 do Consp. Fl. Angol. 1 onde consta a espécie Melhania carrissoi de Exell e Mendonça dedicada a Carrisso; um dos tipos foi colhido por Carrisso \& Sousa em Junho de 1937 no Morro das Paralelas (chama-se a atenção para o ano, mês e local da colheita!).

Para que o Consp. Fl. Angol. fosse/seja uma Flora apenas lhe falta a descrição dos géneros e das espécies. Esse «apenas» deve-se ao facto de o Conspectus ter sido uma obra absolutamente pioneira na Botânica em Portugal, quer pelo volume e complexidade do trabalho envolvido, quer pela colaboração internacional que não era costume no país. Aquando da elaboração da Flora Zambesiaca (Flora que engloba Moçambique, Malawi, Zâmbia, Zimbabué, Botswana e Caprivi Streep, ou seja, os países da bacia hidrográfica do rio Zambeze) em que ainda hoje colaboram Portugal e a 30 Grã-Bretanha foi frisado que «... tinha começado em 1937, por iniciativa do falecido Prof. Carrisso, uma obra regional de natureza florística concernente o território português de Angola - Conspectus Flora Angolensis. Esta obra continuava a velha tradição de colaboração anglo-portuguesa e facilitou as negociações para um trabalho conjunto sobre a flora da Federação das Rodésias e Niassalândia e o seu vizinho oriental, Moçambique» (Dandy \& Taylor, 1960).

Passaram-se quase 7 anos na elaboração deste primeiro fascículo do volume 1 do Consp. Fl. Angol. Durante este tempo tornou-se óbvio que 
2. Mellania velutina Forsk, Fl. Aegypt. - Arab.: 64 (1775). Gossweiler \& Mendonça, Cart. Mitogeogr. Angol.: 160 (1939).

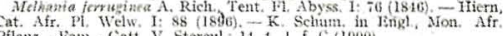

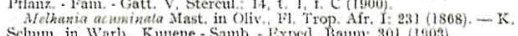
CUBANGO: Cavanga, margens do rio Cubango, Baum 418 BD; BM; Coi; K).

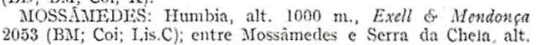
2053 (BMi; Coi; 1.is.C); entre Mossamedes e Serra da Cliena att.
$200 \mathrm{~m}$., Gomes e Sorsa s. 11. (Coi). HUILA: Vila Pereira d'Tça, $1150 \mathrm{~m}$., Exell \& Mendonsa 2839 (BM; Coil; Chibemba, Pearson 2442 (K); Vila Pereira d'Ica,
A. Porcell-Colton 991 (BMI) 1028 (BM); margens do rio Monino,

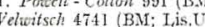

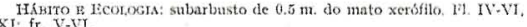
DrsTr. GEociz.: Arábia, Africa tropical oriental, Congo Bejga, Rhodisia

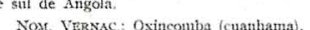

3. Melhania Forbesii Planch ex Mast. in Oliv, F1. 'Trop. Afr. I: (1) Fin . Schum. Exeil in Journ. of Bot. LXV, Suppl. Polypet.: 42 (1927).

LUANDA: Cacuaco, Gosszeciler 1501 (BM: Coi): Caxito, rio s. n. (K); Quicuxe, Weluitsch 4742 (BMI Lis.U), 4743 (BD; BM; Coi: K; Lis.U), col. carp. 286 (BM; I, is.U), 288 (BMI; I, is. U)

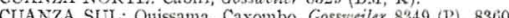
(BD; $B M ; \mathrm{K} ; \mathrm{P}$ ).

IIIniro E FCorncis: erva anual on vivaz do mato aberto xerófilo. Fi e

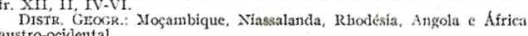

4. Melhania Carrissoi İxell \& Mendonça in Bol. Soc. Brot., Sér. 2. XIII: 310 (1939).- - Gossweiler \& Mendonç, Cart. Fitogeogr. Angol.: $197(1939)$.

MOSSAMEDESS: Pedras Salvadoras, Carrisso \& Sousa 348
(BMI, tipo; Coi; I,is.C); Morro das Paralelas, Carrisso \& Soutsa 354
STRRCUHACEAE

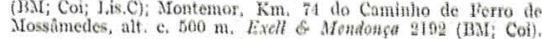

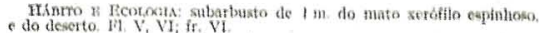

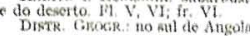

3. MELOCHIA I.,

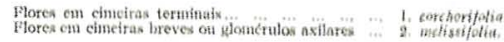

1. Melochia corchorifolia I., Sp. P., I: 075 (1758), - Hierii,

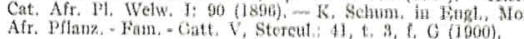

I.UANDA: Junnda, Gossectiler 362 (BD; BM; K).

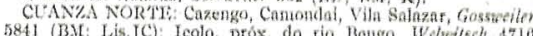

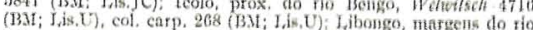
Lifune, Welacitsch 1717 (BD; BM; Coi; $\mathrm{K} ; \mathrm{I}$, is, U).

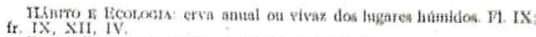

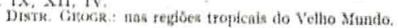

2. Melochia melissifolia Benth. in Mook, Journ, of Bot. IV:

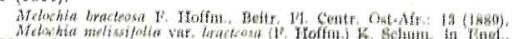

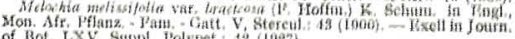

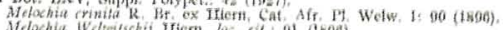

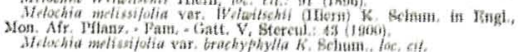

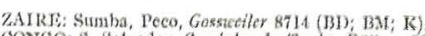

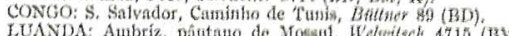
(Coi: K: I, is U). U).

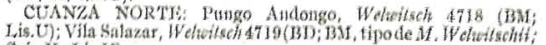

silotia var, brachyphyllat

FiguRA 1 - Conspectus Flora Angolensis (Consp. Fl. Angol.), páginas 190 e 191. Elaborado pelo Instituto Botânico de Coimbra com a colaboração do Museu Britânico (British Museum). Fundado por L. Wittnich Carrisso. Volume 1: fasc. II (1951): Ranunculaceae-Aquifoliaceae por A.W. Exell $\mathcal{E}^{\circ}$ F. A. Mendonça (Flacourtiaceae por H. Sleumer, Dipterocarpaceae por H. Bancroft) 
as expedições florísticas a Angola não se podiam dar por terminadas. Preparou-se, então, a terceira missão. Entre dizer e fazer foi uma distância enorme. Esses anos são descritos pelo seu primeiro Mestre, Palhinha (1938): «De 1930 jusqu'à 1936 je l'ai vu animé et découragé; animé quand il avait la promesse d'obtenir les fonds nécessaires; découragé quand il reconnaissait l'impossibilité de les avoir; mais, travailleur infatigable, apôtre inlassable, il a fait le rôle de Sisyphe pendent six ans, toujours montant la raide côte, ayant sur lui le poids énorme de son désir, pour la redescendre voyant l'inutilité de ses efforts...".

Do ponto de vista científico esta terceira expedição foi a melhor organizada e a mais frutuosa do ponto de vista botânico. Havia mais experiência e melhor conhecimento da área a explorar; os anos de estudo da flora tornaram os objectivos mais precisos; a equipa tinha o número ideal de botânicos experientes.

Em Fevereiro de 1937, poucos dias depois de publicado o primeiro fascículo do Conspectus Flora Angolensis, Carrisso e os seus companheiros de Coimbra partiram de Lisboa rumo a Luanda. Lá juntaram-se a Exell, sua esposa e Gossweiller e iniciaram uma viagem em que colheram cerca de 25.000 exemplares de herbário. Esses exemplares têm sido um contributo precioso para a elaboração do Conspectus (ainda hoje inacabado) e outros estudos florísticos sobre Angola.

No total, as três viagens somaram cerca de $30.000 \mathrm{~km}$, mais do que os $28.000 \mathrm{~km}$ da rede de estradas de Angola à altura. O material de herbário colhido durante estas expedições foi juntar-se às colecções do alemão Friedrich Welwitsch (1806-1861) e Gossweiller constituindo o todo material de referência de uma parte muito interessante de África. De facto, Angola estende-se dos paralelos $5^{\circ}$ (incluindo Cabinda) $-18^{\circ} \mathrm{S}$ e dos meridianos $12^{\circ}-24^{\circ} \mathrm{E}$, ou seja, cobre uma variedade enorme de habitats, da floresta tropical ao deserto, da orla marítima, passando pela longa escarpa até ao vasto planalto interior o qual, no seu extremo este, vê passar o rio Zambeze. Espécies novas descritas de Angola têm muitas vezes distribuição ou em todo o sul da África ou na África central - daí a grande importância destas colecções históricas.

Carrisso foi mais um homem de acção, um explorador, um condutor de homens e eventos, do que um investigador de laboratório ou de herbário. Não deixou muitos artigos científicos escritos pelo seu próprio punho; mas 
ficou memória de várias conferências vibrantes e sempre, sempre frontais na apreciação que fazia da sociedade portuguesa. A acção esteve presente desde cedo na sua vida, velejando na baía de Buarcos.

Segunda-feira, 14 de Junho de 1937. O deserto de Moçâmedes (Namibe) pela terceira vez. Expedição a $102 \mathrm{~km}$ a sul da cidade de Moçâmedes (Namibe). Acampamento a $2 \mathrm{~km}$ do Morro das Paralelas. A expedição subia o morro e colhia plantas. Carrisso sentiu-se mal e foi rodeado por Ana Maria e Jara de Carvalho. A expedição regressou aos veículos, Carrisso pelo seu pé, sem ajuda, já se sentindo melhor. $\grave{A}$ beira da tenda, um cajado numa mão, um molhe de plantas na outra, enquanto lhe preparavam a cama de campanha acabou por concordar que fosse chamado um médico a Moçâmedes (Namibe). Deitou-se e ajeitou-se na cama (Cristão, 1937).

Quem matou Carrisso? O seu coração cansado de tantos trabalhos? A sua personalidade irrequieta? O Portugal lânguido que tantas vezes o terá frustrado?

Não teve filhos. Escreveu livros. Plantou árvores. Semeou ideias, ideias, ideias.

Como corolário das suas actividades em Angola o nome de L. W. Carrisso foi celebrado por vários botânicos em várias espécies novas para a ciência descritas de África, bem como um género.

Espécies:

Acanthaceae: Monechma carrissoi Benoist in Bol. Soc. Brot., ser. 2, 24: 30 (1950) - descrita de Afr. Lusit. Or., ou seja, Moçambique.

AlOACEAE: Haworthia carrissoi Resende in Bol. Soc. Brot., ser. 2, 15: 161 (1941) - descrita da província do Cabo na África do Sul.

Capparacene: Ritchiea carrissoi Exell \& Mendonça in Bol. Soc. Brot. ser. 2, 11: 47 (1936) - descrita de Angola.

Compositae: Bothriocline carrissoi R. Wech. in Bull. Jard. Bot. Belg., 51 (1-2): 112 (1981) - descrita de Angola.

Dipterocarpaceae: Monotes carrissoanus H. H. Bancr. in Journ. Bot., Lond., 77: 110 (1939); \& in Bol. Soc. Brot. 1938-9, ser. 2, 13: 356 (1939) - descrita de Angola.

FAGACEAE: Quercus x carrissoana A. Camus, Les Chenes, Monogr. Gen. Quercus, Atlas, 2. Expl. Pl. (Encycl. Econ. Sylv. 7) 59 (1935) - descrita de Marrocos. 
Leguminosae: Guibourtia carrissoana (Exell) J. Léonard in Bull. Jard. Bot. Brux. 19: 404 (1949) cujo basiónimo é: Copaifera carrissoana Exell ex Gossw. \& Mendonça, Carta Fitogeogr. Angola, 149 (1939), in adnot., nomen; Exell in Bol. Soc. Brot. 1938-9, ser. 2, 13: 323 (1939) - descrita de Angola.

Crotalaria carrissoana Torre in Mem. Junta Invest. Ultram., Lisboa, ser. 2, 19: 44 (1960) - descrita de Angola.

Melastomataceae: Dissotis carrissoi A. Fern. \& R. Fern. in Bol. Soc. Brot., ser. 2, 28: 193 (1954) - descrita de Angola.

Polygalaceae: Heterosamara carrissoana (Exell \& Mendonça) Paiva in Fontqueria, 50: 129 (1998) cujo basiónimo é: Polygala carrissoana Exell \& Mendonça in Bol. Soc. Brot. 1938-9, ser. 2, 13: 307 (1939) - descrita de Angola.

Portulachcene: Ceraria carrissoana Exell \& Mendonça in Bol. Soc. Brot. 1938-9, ser. 2, 13: 309 (1939) - descrita de Angola.

Portulaca carrissoana (Exell \& Mendonça) Nyananyo in Taxon, 35 (3):

592 (1986) cujo basiónimo é: Sedopsis carrissoana Exell \& Mendonça in Bol. Soc. Brot. 1938-9, ser. 2, 13: 308 (1939) - descrita de Angola.

Rubiacene: Coffea carrissoi A. Chev. in Rev. Bot. Appliq., 19: 401 (1939) - descrita de Angola.

STERCUliaceae: Melhania carrissoi Exell \& Mendonça in Carrisso, Consp. Fl. Angol. 1: 190 (1939); \& in Bol. Soc. Brot. 1938-9, ser. 2, 13: 310 (1939) - descrita de Angola.

Tilinceat: Grewia carrissoi Exell \& Mendonça in Bol. Soc. Brot. 19389, ser. 2, 13: 318 (1939) - descrita de Angola.

Vitaceae: Cissus carrissoi Exell \& Mendonça in Bol. Soc. Brot., ser. 2, 26: 227 (1952) - descrita de Angola.

\section{Género:}

Leguminosae: Carrissoa angolensis Baker f. in Bol. Soc. Brot., ser. 2, 8: 108 (1933) - descrita de Angola (provavelmente próxima ou = Eriosema).

Outros nomes foram:

Compositae: Rhaponticoides carrissoi (Rothm.) M. V. Agab. \& Greuter in Willdenowia 33 (1): 60 (2003) cujo basiónimo é: Centaurea carrissoi Rothm. in Bol. Soc. Brot. ser. 2, 13: 281 (1939) - descrita de Portugal.

LABIATAE: Sideritis carrissoana Font Quer in Brotéria, ser. Bot., 22: 95 (1926) - descrita de híbrido de origem cultivada no Jardim Botânico de Barcelona ( $S$. glauca x $S$. granatensis). 


\section{Referências bibliográficas}

Câmara Municipal da Figueira da Foz - Centenário do Nascimento Luiz Wittnich Carrisso. Biblioteca Municipal da Figueira da Foz, 1986.

CARrisso, L. W. - A missão botânica da Universidade de Coimbra à colónia de Angola, em 1927. Bol. Soc. Brot. ser. 2, 6 (1929-30) p. 309-312.

- (1928). Investigação scientífica colonial. Bol. Soc. Geogr. Lisboa. ser. 46, 7-8: 151. Carvalho, A. F. - Prof. Luiz Carrisso. Bol. Soc. Brot. 13, ser. 2 (1939) p. XI-XVI. Chodat, R. \& Carrisso, L. - Une nouvelle théorie de la myrmécophilie. Compt. Rend. Séances Soc. Phys. Genève, 37 (1) (1920), p. 9-12.

Chodat, R., avec la collab. de L. CARrisso, - B. La myrmécophilie des Cordia de la section Gerascanthus. In: CHODAT, R. avec la collab. de w. Vischer R. La végétation du Paraguay: résultats scientifiques d'une mission botanique suisse au Paraguay, Bull. Soc. Bot. Genève, ser. 2, 12 (6-9) (1920), p. 172-200.

Correia, M. - Alguns passos da acção colonial do Prof. Doutor Luiz Carrisso. Bol. Soc. Brot. ser. 2, 13: (1939), p. XVII-XXXI.

Dandy, J. E. ; TAYlor, G. - Prefácio. In: Exell, A. W. ; Wild, H. eds, Fl. Zamb. 1 (1960), p. 7.

Dí́rio De Coimbra de 11 de Julho de 1937.

Fernandes, A. - Notícia sobra a vida e a obra do Prof. Luiz Wittnich Carrisso. Bol. Soc. Brot. ser. 2,13 (1939), p. 4-44.

MendonçA, F. A. - O habitat da Welwitschia mirabilis. Bol. Soc. Brot. ser. 2, 6 (1929-30), p. 320-321.

- Agrostologia de Angola. I - Maydeae e Andropogonae. Bol. Soc. Brot. ser. 2, 10 (1935), p. 3-42.

PalhinHA, R. T. - Luiz Wittnich Carrisso (1886-1937). Bull. Soc. Bot. France. 85 (1938), p. 31- 34.

SchüTt, F. - Analytische Plankton-Studien. Leipzig, 1892. 


\section{Série}

\section{Documentos}

Imprensa da Universidade de Coimbra

Coimbra University Press

2005

- U

C - 